RESEARCH ARTICLE

\title{
Multiple Myeloma Associated with Dermatomyositis: A Short Report and Mini-Review
}

\author{
Md Serajul Islam ${ }^{1,2^{*}}$ and Pavel Kotoucek ${ }^{2}$ \\ ${ }^{1}$ Department of Haematology, Guys' \& St Thomas' Hospital, London, UK \\ ${ }^{2}$ Department of Haematology, Broomfield Hospital, Chelmsford, UK
}

*Corresponding author: Md Serajul Islam, Department of Haematology, Guys' \& St Thomas' Hospital, London, UK; Department of Haematology, Broomfield Hospital, Chelmsford, UK, Tel: +44-7769580452, Fax: +44-1245-51-6669, E-mail: serajul@doctors.org.uk

\begin{abstract}
Multiple myeloma (MM) is characterized by the neoplastic proliferation of plasma cell clones that produce monoclonal immunoglobulin. Dermatomyositis (DM), and to a lesser extent polymyositis (PM), carry a higher risk of cancer than that of the general population as demonstrated by several studies with the prevalence being $32 \%$ and $15 \%$ for DM and $\mathrm{PM}$ respectively. The mechanism underlying the association between idiopathic inflammatory myopathies (IIM) and malignancies remains unclear. Both conditions predominantly affect adults. About $15 \%$ of DM is refractory to conventional drug therapy and rituximab has been used successfully in those cases as it was in our patient. To our knowledge none of the cases of DM associated MM has been reported in literature where preceding DM were so extensively treated as in our patient. Our report is also unique as none of the cases reported in literature received rituximab- a monoclonal anti-CD20 antibody treatment prior to development of MM which may have some bearing in the development of subsequent MM.
\end{abstract}

\section{Keywords}

Multiple myeloma, Dermatomyositis, Autoimmune diseases, Polymyositis

\section{Introduction}

$\mathrm{MM}$ is characterized by neoplastic proliferation of plasma cells involving more than $10 \%$ of the bone marrow [1]. Increasing evidence suggests that the bone marrow microenvironment of tumour cells plays a pivotal role in the pathogenesis of myelomas [2]. In its symptomatic phase is associated with significant end organ damage including lytic bone lesions, anaemia, and loss of kidney function, immunodeficiency, and amyloid deposits in various tissues [3]. The American Cancer Society has estimated that 30,770 new MM cases will occur in the United States in 2018, with an estimated 12,770 deaths [4]. Idiopathic inflammatory myopathies (IIM), a heterogeneous group of disorders characterised by weakness and inflammation of skeletal muscle, are often associated with malignancies [5]. Polymyositis (PM) and dermatomyositis (DM) are classified as IIM, with these conditions predominantly affecting adults [6]. Their aetiology is undetermined, and they present with characteristic muscle and cutaneous manifestations. Dermatomyositis, and to a lesser extent PM, carry a higher risk of cancer than that of the general population as demonstrated by several studies $[7,8]$. The mechanism underlying the association between IIM and malignancies remains unclear. According to the cohort study conducted in Sweden, Denmark and Finland by Hill and colleague's malignancies were found in 198 out of 618 patients with the prevalence being $32 \%$ and $15 \%$ for DM and PM respectively [7]. The mechanism of association between IIM and malignancy remains unclear. A model of crossover immunity between tumour cells and myofibroblasts explains the parallel clinical course and the diagnostic utility of detection of myositis autoantibody in predicting the risk of malignancy [9].

Meta-analysis of four reports in 1994, by Zantos and colleagues, showed that in a total of 1078 myositis patients (565 patients with DM, 513 patients with PM) odds ratios of 4.4 (95\% $\mathrm{Cl} 3-6.6)$ of DM with malignancies and PM group odds ratio was 2.1 (95\% Cl 1.4-3.3)

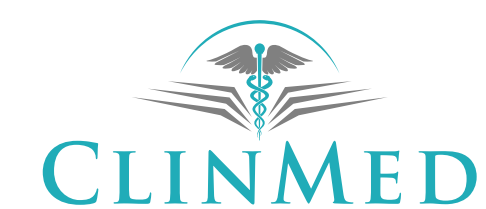

INTERNATIONAL LIBRARY
Citation: Islam MS, Kotoucek P (2018) Multiple Myeloma Associated with Dermatomyositis: A Short Report and Mini-Review. Int J Blood Res Disord 5:029. doi.org/10.23937/2469-5696/1410029 Accepted: June 18, 2018: Published: June 20, 2018

Copyright: (C) 2018 Islam MS, et al. This is an open-access article distributed under the terms of the Creative Commons Attribution License, which permits unrestricted use, distribution, and reproduction in any medium, provided the original author and source are credited. 
[10]. However, very few cases of DM associated with multiple myeloma were reported in literature [8-13] and one study showed only 1 out 32 patients with IIM had myeloma [13] and one case report on non-secretory myeloma associated with IIM been reported [11]. To our knowledge none of the cases of DM associated MM has been reported in literature where preceding DM were so extensively treated as our patient. None of the reported cases received rituximab-a humanised monoclonal antibody which binds to CD20 antigen on B lymphocytes. Rituximab is widely being used in combination with chemotherapy for B cell Non-Hodgkin's as this lymphoma cell express CD20 antigen. Use of rituximab in IIM is limited. However significant group of around 15\% of DM patients $[14,15]$ who are inadequately controlled by conventional therapy responded to rituximab. Prior Rituximab treatment for DM in our patient may have some bearing in the development of subsequent MM.

\section{Method and Material}

Google search, PubMed, google scholar were systemically searched for literature from 1965 to March 2018 published in English language using search words myeloma, multiple myeloma MGUS, plasma cell neoplasia, autoimmune, autoimmune disease/disorders, dermatomyositis, polymyositis, rheumatoid, systemic sclerosis. Various combinations of these words are used in the search. Case reports, case series, and population-based studies, randomised trials, and retrospective case series all taken into consideration. Article with only abstract was excluded.

\section{Case Report}

58-years-old man was referred to our haematology unit for investigation of positive urine Bence Jones protein. This test was carried out by his primary care physician for investigation of lower back pain which was subsequently transpired out to be due to his spinal canal stenosis. When he was seen in haematology clinic he

Table 1: Blood results.

- Creatinine $88 \mathrm{umol} / \mathrm{L}$,

- Adjusted calcium $2.45 \mathrm{mmol} / \mathrm{L}$,

- Albumin $41 \mathrm{~g} / \mathrm{L}$,

- FBC:

haemoglobin $138 \mathrm{~g} / \mathrm{L}$,

white blood cell count $8.5 \times 109 / \mathrm{L}$,

platelets $335 \times 109 / \mathrm{L}$,

- Serum protein electrophoresis: No monoclonal band.

- Beta 2 Microglobulin- $2.1 \mathrm{mg} / \mathrm{L}$

- Free light chain analysis

kappa free light chain level 322.49 mg/L (range 3.319.4),

lambda free light chain level $7.34 \mathrm{mg} / \mathrm{L}$ (range 5.726.3) and

kappa lambda ratio was elevated at 43.94 (range 0.26-1.65).

FBC: Full Blood Count. gave no history of bone pain, no pathological fracture, denied any B symptoms. He also denied any history of lumps or bumps. His physical examination in clinic did not reveal any palpable lymph nodes or any organomegaly or any other mass. Although he had proximal muscles weakness in his legs due to dermatomyositis as well as long use of high dose steroid.

His blood results are shown in Table 1.

Low dose CT skeletal survey did not show any osteolytic lesions. A bone marrow biopsy showed increased in plasma cells which were kappa light chain restricted and showed positive reaction to CD138, CD56 and cyclin D1. Hence a diagnosis of stage 1 ISS asymptomatic myeloma was made and continued expectant management for myeloma.

He man has past medical history of long standing DM which was diagnosed in 2004. This condition proved to be very fulminating in nature and showed intractable characteristic in the form that it was very difficult to control and the letters from rheumatologist stated that he failed treatment with intravenous cyclophosphamide, high doses of steroids, immunoglobulin infusion, mycophenolate mofetil (MMF) as well as methotrexate. In January 2006 he was treated in desperation with intravenous rituximab with excellent response to his symptoms of muscle pain and weakness and one of the rheumatology letter stated that "Indeed it probably saved his life". Our patient is probably among the $15 \%$ of IIM case who does not respond to conventional treatment and studies have showed that this group of patients responds to biologic agent like rituximab $[14,15]$. Unfortunately, despite being maintained on high dose steroid as well as MMF he required further doses of rituximab in 2008, 2010, 2014 and again in 2016 for further flare up of his DM.

\section{Discussion}

MM accounts for approximately $1.8 \%$ of all cancers and slightly more than $17 \%$ of hematologic malignancies in the United States [4]. MM is slightly more common in men than in women and is twice as common in African-Americans compared with Caucasians [16]. The median age of patients at the time of diagnosis is about 65 years [17]. The diagnosis of symptomatic multiple myeloma requires the presence of one or more myeloma defining events (MDE) in addition to evidence of either $10 \%$ or more clonal plasma cells on bone marrow examination or a biopsy-proven plasmacytoma $[1,18]$. MDE consists of established CRAB (hypercalcaemia, renal failure, anaemia, or osteolytic bone lesions) features as well as 3 specific biomarkers: Clonal bone marrow plasma cells $\geq 60 \%$, serum free light chain (FLC) ratio $\geq 100$ (provided involved FLC level is $\geq 100 \mathrm{mg} / \mathrm{L}$ ), and more than one focal lesion on magnetic resonance imaging (MRI). The updated criteria represent a paradigm shift since they allow early diagnosis and initiation of therapy before end-organ damage [18]. 
Several studies have investigated the hypothesis that repeated or chronic stimulation of the immune system may lead to MM [19-21]. One study showed that significantly elevated risks of MM and its precursor condition monoclonal gammopathy of undetermined significance (MGUS) - a pre-malignant condition where bone marrow plasma cell is $<10 \%$ are associated with broad categories of autoimmune, infectious, and inflammatory disorders [22].

Why IIM predispose to the development of MM is poorly understood. However, it has been suggested that most B-cell neoplasm including MM derive from post- germinal center (GC) cells which are undergoing somatic hypermutation and class switch recombination [23]. As a result, B-cell neoplasms originating from GC cells are most responsive to autoimmune stimulation and that might explain to some extent the association of MM and IIM [24-29]. Many cancers are increased in AIDs patients for reasons that are not known $[13,30]$. The immunological disturbances in autoimmune diseases (AIDs) may be an important mechanism to cancer formation because cancers typically arise in organs with Al manifestations $[13,30]$. However, treatment with immunosuppressive therapy as was the case in our patient may also contribute [31].

Evidence suggests that B lymphocytes play an important role in the pathogenesis of DM. Muscle biopsy specimens exhibit a predominance of perivascular B cells [32] and up to $40 \%$ of patients with DM have detectable myositis-specific autoantibodies [33,34]. Hence the rationale for rituximab use in our patient for intractable DM which has failed other treatment modalities. Whether rituximab has played any role in the pathogenesis of myeloma development is not clear however there is reported case of accelerated progression of myeloma after rituximab treatment [31]. Many AIDs are treated with non-steroidal anti-inflammatory drugs (NSAID) and as these are protective against many cancers [35] they may help to hide carcinogenic effects of AIDs or may delay the develop myeloma or other malignancies as in our patient who is on regular NSAID for pain control [35]. Myeloma arises from B-cells with somatic hypermutations in the variable region immunoglobin genes [34]. Studies on survival of MM after rheumatoid arthritis, Crohn disease, ulcerative colitis and psoriasis have shown no effect on myeloma survival [36-38]. However, there is no prospective study to show DM affect MM survival. However, one population-based study showed impaired MM survival associated with DM [39].

There has been a report that treatment of MM with high dose chemotherapy followed by autologous stem cell transplant (ASCT) also treats the paraneoplastic condition like myositis [40] which should be kept in mind when challenged by intractable dermatomyositis like our patient. One study showed that in patients with $\mathrm{MM}$ and a prior autoimmune disease, the risk of death was significantly increased, $\mathrm{HR}=1.2(95 \% \mathrm{Cl} 1.2$ 1.3) compared to MM patients with no history of autoimmunity [39]. Negative impact on survival in MM associated with DM could be due to shared underlying common genetic factors, or that patients with a history of autoimmunity develop more severe cases of MM, fortunately our patient remain asymptomatic from MM point of view [39].

\section{Conclusion}

Future research is required to explore further the link between MM and AIDs like DM. Inflammation in the setting of autoimmunity may serve as a trigger for MM. In addition, a common genetic susceptibility for developing both DM and MM might also exist. Autoimmune hematologic and rheumatologic diseases may pose important clinical problems for the MM patients. Therefore, a catalogue of these problems is important so that physicians are able to consider, identify and address them promptly and underlines the need for studies aimed at tailoring therapy according to co-morbidity.

\section{Funding}

Nothing to declare.

\section{Author Contribution}

MSI has conceived the articles, reviewed literature and written the initial draft of the manuscript, PK edited the manuscript, reviewed literature. Both author agreed on the final content of the manuscript.

\section{Conflict of Interest}

None declared.

\section{References}

1. Rajkumar SV (2016) Updated diagnostic criteria and staging system for multiple myeloma. Am Soc Clin Oncol Educ Book 35: e418-e423.

2. Raab MS, Podar K, Breitkreutz I, Richardson PG, Anderson KC (2009) Multiple myeloma. Lancet 374: 324-339.

3. Malpas JS, Bergsagel DE, Kyle R, Anderson K (2004) Multiple myeloma: biology and management. Oxford: Oxford University Press.

4. https://www.cancer.org/cancer/multiple-myeloma/about/ key-statistics

5. Buchbinder R, Forbes A, Hall S, Dennett X, Giles G (2001) Incidence of malignant disease in biopsy-proven inflammatory myopathy. A population-based cohort study. Ann Intern Med 134: 1087-1095.

6. Dalakas MC, Hohlfeld R (2003) Polymyositis and dermatomyositis. Lancet 362: 971-982.

7. Hill CL, Zhang Y, Sigurgeirsson B, Pukkala E, Mellemkjaer $L$, et al. (2001) Frequency of specific cancer types in dermatomyositis and polymyositis: A population-based study. Lancet 357: 96-100.

8. Stockton D, Doherty VR, Brewster DH (2001) Risk of cancer in patients with dermatomyositis or polymyositis, and follow-up implications: A Scottish population-based cohort study. Br J Cancer 85: 41-45. 
9. Chinoy $H$, Fertig $N$, Oddis CV, Ollier WE, Cooper RG (2007) The diagnostic utility of myositis autoantibody testing for predicting the risk of cancer- associated myositis. Ann Rheum Dis 66: 1345-1349.

10. Zantos D, Zhang Y, Felson D (1994) The overall and temporal association of cancer with polymyositis and dermatomyositis. J Rheumatol 21: 1855-1859.

11. Prakash MS, Baliga KV, Singh AP, Mishra DK (2002) Non-secretory multiple myeloma with hypercalcemic acute renal failure. J Assoc Physicians India 50: 1330-1331.

12. Borgia F, Vaccaró M, Guarneri F, Cannavó SP, Guarneri B (2001) Dermatomyositis associated with IgG myeloma. $\mathrm{Br}$ J Dermatol 144: 200-201.

13. Yang Y, Chen L, Jia Y, Liu Y, Wen L, et al. (2018) Monoclonal gammopathy in rheumatic diseases. Clin Rheumatol 37: 1751-1762.

14. Allenbach Y, Guiget M, Rigolet A, Marie I, Hachulla E, et al. (2015) Efficacy of rituximab in refractory inflammatory myopathies associated with Anti-Synthetase Auto-Antibodies: An Open-Label Phase II Trial. PLoS One 10: e0113702.

15. Vermaak E, Tansley SL, McHugh NJ (2015) The evidence for immunotherapy in dermatomyositis and polymyositis: A systematic review. Clin Rheumatol 34: 2089-2095.

16. Kyle RA, Gertz MA, Witzig TE, Lust JA, Lacy MQ, et al. (2003) Review of 1027 patients with newly diagnosed multiple myeloma. Mayo Clin Proc 78: 21-33.

17. Kyle RA, Rajkumar SV (2007) Epidemiology of the plasma-cell disorders. Best Pract Res Clin Haematol 20: 637664.

18. Rajkumar SV, Dimopoulos MA, Palumbo A, Blade J, Merlini $G$, et al. (2014) International myeloma working group updated criteria for the diagnosis of multiple myeloma. Lancet Oncol 15: e538-e548.

19. Marie I, Guillevin L, Menard JF, Hatron PY, Cherin P, et al. (2012) Hematological malignancy associated with polymyositis and dermatomyositis. Autoimmun Rev 11: 615-620.

20. Brown LM, Gridley G, Check D, Landgren O (2008) Risk of multiple myeloma and monoclonal gammopathy of undetermined significance among white and black male United States veterans with prior autoimmune, infectious, inflammatory, and allergic disorders. Blood 111: 3388-3394.

21. Landgren O, Weiss BM (2009) Patterns of monoclonal gammopathy of undetermined significance and multiple myeloma in various ethnic/racial groups: Support for genetic factors in pathogenesis. Leukemia 23: 1691-1697.

22. Lewis DR, Pottern LM, Brown LM, Silverman DT, Hayes RB, et al. (1994) Multiple myeloma among blacks and whites in the United States: The role of chronic antigenic stimulation. Cancer Causes Control 5: 529-539.

23. Nair S, Branagan AR, Liu J, Boddupalli CS, Mistry PK, et al. (2016) Clonal immunoglobulin against lysolipids in the origin of myeloma. N Engl J Med 374: 555-561.

24. Koepsell TD, Daling JR, Weiss NS, Taylor JW, Olshan AF, et al. (1987) Antigenic stimulation and the occurrence of multiple myeloma. Am J Epidemiol 126: 1051-1062.

25. Linet MS, Harlow SD, McLaughlin JK (1987) A case control study of multiple myeloma in whites: Chronic antigenic stimulation, occupation, and drug use. Cancer Res 47: 2978-2981.

26. Landgren O, Linet MS, McMaster ML, Gridley G, Hemminki $\mathrm{K}$, et al. (2006) Familial characteristics of autoimmune and hematologic disorders in 8,406 multiple myeloma patients: A population-based case-control study. Int J Cancer 118: 3095-3098.

27. Seifert M, Scholtysik R, Kuppers R (2013) Origin and pathogenesis of $B$ cell lymphomas. Methods Mol Biol 971: 1-25.

28. Hemminki K, Liu X, Forsti A, Ji J, Jas S, et al. (2012) Effect of autoimmune diseases on incidence and survival in subsequent multiple myeloma. Journal of Hematology \& Oncology 5: 59.

29. Hemminki K, Liu X, Forsti A, Ji J, Jan S, et al. (2013) Subsequent leukaemia in autoimmune disease patients. $\mathrm{Br} \mathrm{J}$ Haematol 161: 677-687.

30. Fallah M, Liu X, Ji J, Forsti A, Sundquist K, et al. (2014) Autoimmune diseases associated with non- Hodgkin lymphoma: A nationwide cohort study. Ann Oncol 25: 2025-2030.

31. Korte W, Jost C, Cogliatti S, Hess U, Cerny T (1999) Accelerated progression of multiple myeloma during anti-CD20 (Rituximab) therapy. Ann Oncol 10: 1249-1250.

32. Botet JC, Grau JM, Casademont J, Urbano-Márquez A, Rozman C, et al. (1988) Characterization of mononuclear exudates in idiopathic inflammatory myopathies. Virchows Arch A Pathol Anat Histopathol 412: 371-374.

33. Sarkar K, Miller FW (2004) Autoantibodies as predictive and diagnostic markers of idiopathic inflammatory myopathies. Autoimmunity 37: 291-294.

34. Morgan GJ, Walker BA, Davies FE (2012) The genetic architecture of multiple myeloma. Nat Rev Cancer 12: 335348.

35. Rothwell PM, Fowkes FG, Belch JF, Ogawa H, Warlow CP, et al. (2011) Effect of daily aspirin on long-term risk of death due to cancer: Analysis of individual patient data from randomised trials. Lancet 377: 31-41.

36. Ji J, Liu X, Sundquist K, Sundquist J (2011) Survival of cancer in patients with rheumatoid arthritis: A follow-up study in Sweden of patients hospitalized with rheumatoid arthritis 1 year before diagnosis of cancer. Rheumatology (Oxford) 50: 1513-1518.

37. Shu X, Ji J, Sundquist J, Sundquist K, Hemminki K (2011) Survival in cancer patients hospitalized for psoriasis: A population-based cohort study in Sweden. $\mathrm{Br} J$ Dermatol 165: 129-136.

38. Shu X, Ji J, Sundquist J, Sundquist K, Hemminki K (2011) Survival in cancer patients hospitalized for inflammatory bowel disease in Sweden. Inflamm Bowel Dis 17: 816-822.

39. Lindqvist $\mathrm{E}$, Landgren $\mathrm{O}$, Lund $\mathrm{SH}$, Turesson I, Hultcrantz $M$, et al. (2017) History of autoimmune disease is associated with impaired survival in multiple myeloma and monoclonal gammopathy of undetermined significance: A population-based study. Ann Hematol 96: 261-269.

40. R Chakraverty, N Rabin, K Peggs, Robinson S, Duncan JR, et al. (2001) Dermatomyositis and sarcoid-like reaction associated with multiple myeloma treated effectively by highdose chemotherapy and autologous peripheral blood stem cell transplantation. Bone Marrow Transplant 27: 12151217. 